\title{
Social Representations of Cancer in the Perception of Students Who Attend Brazilian Public Schools
}

\author{
Eduardo Blanco Cardoso and Flávia Inês Schilling \\ School of Education, University of São Paulo (USP), Brazil
}

\begin{abstract}
As an illness, cancer is strongly established in the social imagination. Individuals build ideas from medical, social, and media discourses, which makes it sometimes difficult for them to comprehend the subject. Educational interventions have focused on disseminating information concerning the disease but have remained indifferent to its social connotations. The present study aimed to identify the presence and temporal change of the social representations about cancer among 980 adolescents from Brazilian public and private schools. To this end, a voluntary and anonymous questionnaire was applied so that a quantitative and statistical evaluation could be performed. In general, the results indicate that negative social representations concerning the disease predominate in younger age groups. This tendency is gradually reduced as students grow older. Social representations are not static but change structurally, depending on the surroundings and social contexts. Family, the media, and teachers are the main sources of information. In this context, a pessimistic view regarding the disease is prevalent among men. Generally, the disease is seen from three perspectives. "Destruction" centers on statements concerning death, especially when a family member or friend has the disease. The "incurability" perspective associated with death is equally divided among the opinions on the binomials of life/death and heal/get sick. Finally, "resolution" or cure depends on early diagnosis and treatment. Although there is a consensus at this aspect, most perceptions describe the disease as negative, responsible for the loss of hair and weigh, being more severe in females and occasionally associated with a divine punishment. The obscure logic of contagion appears in the discourse of lay people as a possible means of transmission. These findings reflect the unique structure of the representations in a population of adolescents, which in some cases, may hinder an understanding of the benefits of preventive behaviour.
\end{abstract}

Keywords: Social representations; Social interaction; Cancer; Adolescence

\section{Introduction}

Cancer is the cause of approximately $14 \%$ of all deaths in the world $[1,2]$. In Brazil, according to data from the National Cancer Institute [3], the estimate for the $2016 / 2017$ biennium is 600,000 new cases, including cases of non-melanoma skin cancer, which enhances the magnitude of the problem. Given that changes in certain people's behaviours can have a positive effect on reducing morbidity and mortality through the incorporation of protective life habits, preventive practices, and screening tests, health policy must also be oriented to promote the changes that favour the development of early detection practices and treatment of the disease, as well as follow-up and rehabilitation. For these actions to be successful, it is necessary to contemplate the sociocultural characteristics of the population, its perceptions, beliefs, and social representations in relation to the disease.

In Latin America, generally and in Brazil particularly, beliefs and social representations concerning cancer constitute a rarely considered topic. The available studies focus on the analysis of the perspectives and experiences of patients or the people who have suffered from the illness, including family, friends, and caregivers, as well as the views of doctors and health professionals.

The mass media and the technological development of society support the extensive dissemination of statistical data that promote hope and fear, including various factors from the environment and individuals. Obesity, hormones, intake of animal fats and toxic substances, and exposure to ionizing radiation, bacteria, viruses, and environmental pollution, among other health issues, are cited as triggers or predisposing factors of the disease. Other factors that are inherent to the host, such as inherited traits, immunity, ethnicity, age, gender, occupation, and lifestyle habits, are also cited. However, people are not properly prepared to "assimilate" and "integrate" such a wide range of information. For unprepared citizens, all of this information, in addition to a precarious health system with poor outcomes, discourages the adoption of preventive health measures. This discouragement is an expression of a lack of knowledge and reliable information and users' inability to obtain, in a timely manner, a consultation or treatment [4]. However, the hypothesis that ignorance is the reason for the presence of risk factors for chronic diseases, particularly cancer, seems to be insufficient, despite being upheld by the hegemony of medical and epidemiological discourse. The psycho-social notion of resistance to change is also an insufficient cause, which presupposes the adoption of well-established standards and skills for a new level of action, namely, prevention. The idea of resistance to a "change of behaviour" is not the most appropriate explanation. The concept of cancer as "a hard-to-cure disease" likely rests on the pillars of popular culture and the economy and is especially observable in times of crisis similar to the crisis that Brazil currently faces. An individual is both an agent of social change and a product of it. Therefore, the answers and conduct of individuals are incorporated into and built on the grounds of social reality. In the 20th century and at the beginning of the $21^{\text {st }}$ century, cancer has

*Corresponding author: Eduardo Blanco Cardoso, School of Education, University of São Paulo (USP), Brazil, Tel: 005511997616641; Fax: 00551130858672; E-mail: blancoec@uol.com.br

Received July 07, 2017; Accepted August 07, 2017; Published August 10, 2017

Citation: Cardoso EB, Schilling FI (2017) Social Representations of Cancer in the Perception of Students Who Attend Brazilian Public Schools. J Health Educ Res Dev 5: 224. doi: 10.4172/2380-5439.1000224

Copyright: (c) 2017 Cardoso EB, et al. This is an open-access article distributed under the terms of the Creative Commons Attribution License, which permits unrestricted use, distribution, and reproduction in any medium, provided the original author and source are credited. 
been described in the media, literature, and popular discourse as a type of evil force, which is unrestrained and chaotic, that consists of "primitive" and atavistic cells that behave "uninhibitedly" by destroying the natural order of the body and society [5]. Upgraded from its status as a disease and contextualized as an "enemy" with consciousness and a will (because it "can take advantage of ...", "feeds on ...", and "chooses to..."), cancer raises fears in the healthy population and strengthens the established myths surrounding it and in the people who suffer from it. Although it is important and crucial to identify the disease's impact on patients and their families, which has been done, it is also important to recognize its impact on young, healthy people because the ideas that people have about cancer influence how they will come closer to or retreat from health care [6]. An even greater challenge is to bring "adolescents" into the scenario by studying the social representations that cancer induces. In a way, identifying and recognizing these social representations will lead to ideas on how they influence preventive conduct. Simultaneously, the study of social representations provides information to guide the communication strategy in cancer control programs, which is adjusted to the cultural characteristics of the population that is under study. Although the disease is rare in this age group, it is vital to promote proactive behaviour and attitudes concerning healthcare, such as promoting healthy lifestyles and an awareness of early detection programs, given that the absence of healthy habits is one of the main determinants of cancer in adult life.

\section{Objectives}

To identify the presence and temporal change of the social representations concerning cancer in a group of "adolescents" who attend public and private schools.

\section{Methodology}

This is a cross-sectional, descriptive study that uses a quantitative approach. The sample comprised 980 students who were aged between 12 and 18 years; they came from 5 schools ( 3 public and 2 private). For the data collection, a self-administered, individual, voluntary, and anonymous questionnaire was used that consisted of 37 closed questions, whose preparation was based on the recommendations of Armstrong et al. [7]. The research was approved by the Human Research Ethics Committee of the Institute of Psychology at the University of São Paulo (Certificate of Presentation for Ethical Appreciation: 24606813.8.0000.5561 - Plataforma Brasil).

The classificatory variables are presented in tables that contain frequencies and percentages. Moreover, a logistic regression model is employed. This model uses a categorical variable (the presence or absence of some characteristic) as a response variable and detects which variables are significant in the model.

\section{Results}

\section{Score for the negative image of the disease according to age}

The negative image that is generated by the disease is identified through the development of a score that groups the responses to certain sentences in the questionnaire (for true or false concepts). The students with higher scores (fewer correct answers) have a more negative image.

Among younger students, the view on cancer is more negative. The age group of 18 years had few students, and it was disregarded. The negative image score decreased with increasing age, as shown in Figure 1.

\section{The influence of students' institutional origin (public and private) on the type of response}

The students' institutional origin seems to considerably influence the answers, as shown on Table 1. Public school students have more "mystified" thoughts than private school students. For example, the students from public schools answered "yes" at a much higher rate to the following sentence (\#23): "It is not good to talk about cancer because it attracts the disease".

Public school students believe that cancer is a disease that leads to hair and weight loss (88\%). They also tend to think that one should not use the dishes and utensils that belong to cancer patients (57\%) and that one must wash their hands after any physical contact with cancer patients (55\%). In this context, public school students believe that animals and food can transmit the disease (34\% and 28\%). The percentage of students who think that cancer is a punishment from God is also significant in public schools (14\%).

\section{Sources of cancer information for students}

The percentage distribution of the "sources" of cancer information in public and private schools is shown in Table 2. In all schools, the family represents an important source of information. More than half of the students obtained information on cancer through the family. Practically all students, both in public and private schools, heard about

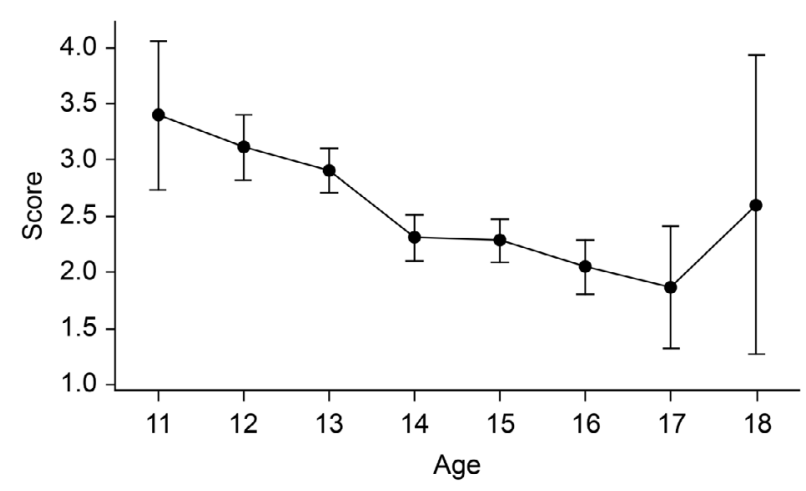

Negative image score $95 \%$ confidence interval around the mean y-axis: Score; $x$-axis: Age

Figure 1: Average negative image score of cancer for every age.

\begin{tabular}{|c|c|c|}
\hline & $\begin{array}{c}\text { Public school } \\
\mathbf{( \% )}\end{array}$ & $\begin{array}{c}\text { Private school } \\
\mathbf{( \% )}\end{array}$ \\
\hline No need to see a doctor & 13 & 10 \\
\hline With money, there is a cure & 25 & 22 \\
\hline There is no cure, with or without money & 50 & 42 \\
\hline It is not good to talk about cancer & 15 & 4 \\
\hline In another country, there is a cure & 16 & 1 \\
\hline It is a bad disease & 89 & 88 \\
\hline It is more severe in women & 53 & 28 \\
\hline It is more severe in men & 12 & 11 \\
\hline It causes hair and weight loss & 88 & 45 \\
\hline Cancer is contagious & 28 & 0 \\
\hline It is caused by eating spoiled food & 28 & 13 \\
\hline Hands should be washed after contact & 55 & 8 \\
\hline One should not use the same plates and & 57 & 1 \\
\hline glasses & 14 & \\
\hline It is a punishment from God & & 9 \\
\hline
\end{tabular}

Table 1: Students' thoughts in relation to cancer. 
this topic on television, although the students in private schools have more access to television.

\section{A family history of cancer negatively influences the view of cancer patient survival}

Table 3 shows the percentage distribution of the responses that were obtained from the students according to the presence or absence of a family history of the disease.

The students at both types of schools with a family history of cancer are less optimistic concerning the survival of cancer patients.

\section{A negative view is prevalent among male students}

Male students tend to have higher negative image scores of cancer than female students, as shown in Figure 2.

Based on the graph above, women have more knowledge than men regarding the different types of existing cancers.

\section{Discussion}

The chosen subject is interesting given its intention to achieve a deeper insight into the representations that are made by a population

\begin{tabular}{|c|c|c|}
\hline Source & Public school (\%) & Private school (\%) \\
\hline Family & 68 & 78 \\
\hline TV & 56 & 72 \\
\hline Internet & 33 & 60 \\
\hline Teacher & 40 & 42 \\
\hline Newspaper & 43 & 32 \\
\hline Friends & 30 & 45 \\
\hline Doctor & 33 & 22 \\
\hline Magazine & 29 & 32 \\
\hline Another source & 4 & 14 \\
\hline
\end{tabular}

Table 2: Comparison between public and private schools of the sources of information regarding "cancer".

\begin{tabular}{|c|c|c|c|}
\hline \multicolumn{2}{|c|}{} & \multicolumn{2}{|c|}{ Is the patient going to die? } \\
\hline School & History & No (\%) & Yes (\%) \\
\hline Public & No & 71 & 29 \\
\hline & Yes & 65 & 35 \\
\hline Private & No & 75 & 25 \\
\hline & Yes & 70 & 30 \\
\hline
\end{tabular}

Table 3: Distribution of the responses concerning a reported family history of cancer.

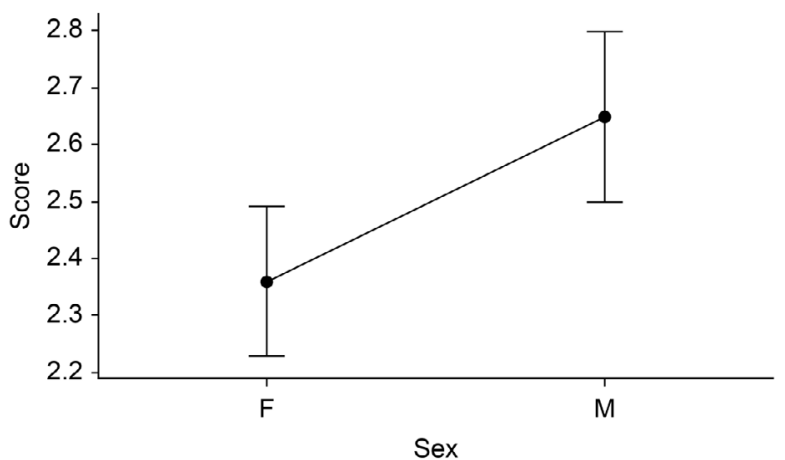

Negative image score $95 \%$ confidence interval around the mean y-axis: Score; x-axis: Sex

Figure 2: Average negative image score of cancer according to gender. on a particular, enigmatic, and frightening disease that is surrounded by many myths and some prejudice. However, for a fact or phenomenon such as cancer to become a social representation, it must be relevant, it must become an object of discussion, and it must provoke amazement and discomfort. As Wolfgang Wagner affirms, "it must cause changes in the routine and in the pattern of behaviour of individuals or groups" [8]. Cancer has been reflected on for some time in the world and in Brazil but has urgently re-emerged considering the high incidence and mortality that are attributed to the disease [9]. Thus, it is not surprising that cancer is an object of social representation because it affects one of the most valued assets of humanity: health.

Social representations as a type of knowledge allude to process and content. As a process, social representations refer to a particular way of acquiring and communicating knowledge. As content, they are linked to a particular domain that consists of a universe of beliefs in which information, representation, and attitude are distinguished. The premise is that the social representations form a totality from these three dimensions, which cannot be understood in isolation. Thus, there is a need to address these dimensions altogether in an articulate and coherent manner.

For this particular research, "information" relates to the organization of the knowledge that a group has on a given social object, in this case, cancer. The products of this "information" are the negative representations concerning the disease, which predominate in the lower age groups; this tendency is gradually reduced as children grow older (Figure 1). Certainly, a person's understanding becomes more consistent as he or she progresses in the acquisition of socially constructed knowledge. Therefore, it is possible to make a precise differentiation between the different grades of education. Each age/ grade expresses a certain amount of information, which can be identified with a "score", such as in the present research.

The dimension that is designated by the term "representation field", which was created by Moscovici [10], refers to the idea of an image, a social model, in the concrete and limited context of the explanations that pertain to a precise aspect of the object of representation, which in this case, is "cancer"; that is, how cancer is, in fact, interpreted. In this sense, cancer's representation concerns issues that relate to preestablished beliefs, namely, physical changes (hair loss and thinning), the possibilities of transmission (through physical contact with the personal objects of cancer patients), and divine punishment, among others (Table 1). The attributed "representation field" encompasses the image that is associated with the ascendancy of the concept that "everyone has cancer", "it is better not to talk about it", and a "God who can make concessions or punish", which were expressions that were commonly identified by the students.

The evaluative-affective orientation or attitude that is assumed by interviewees is identified with a negative image of the disease that, as indicated before, changes with the advancement of age and, consequently, with cognitive-social development. From the point of view of its genesis, "attitude" has been shown to precede the other dimensions of representation because when individuals represent "something", they represent it immediately and by depending on the position that they assume in relation to this "something" [11]. The "affective" elements that are shared by the students are therefore important and play a structuring role in the construction of the material and ideational reality in relation to the disease. Indirectly, in terms of the beliefs that are shared by a small group of students, the intention of "isolating" the cancer patient, who presumably suffers from a "contagious disease", is suggested. Furthermore, the students 
avoid naming the disease and fear it. The untamed quality of fear is what makes cancer contagious. In a way, the logic of contagion is dual. Externally, this logic explains how the process of representation propagates through imitation and, thus, the sudden negative social reaction in relation to the disease. Internally, this logic of contagion refers to the subjective experience that makes people withdraw from the sick because of feelings of sorrow, indignation, and impotence, which revitalizes erroneous ideas concerning horizontal transmission. Actually, "withdrawal" is the action that stigmatizes.

The three dimensions that have thus been explored provide an initial approximation concerning the content and meaning of cancer. In addition, these dimensions denounce some criteria, which the respondents are a part of, with a higher proportion of confused thoughts among the students of public schools.

The transition from the negative view that the disease imposes is gradual and steadily surpassed. The differences in the responses indicate changes in the group's perception, i.e., in the premises that different ages have on the subject, which is an expression of varying degrees of personal development and maturation. In this transition, the youth undergo many situations that appear to mediate, in a relatively meaningful way, the set of representations and the behaviors that correlate to them.

However, the representations are not static, and their dimensions cannot be described separately because they depend on the social conditions in which the subjects develop their everyday life. These representations are dynamic and interpreted through their connections with the surroundings and contexts that influence people's lives. Contemporary society is characterized by the intensity and fluidity of change and communications, by the development of science and technology, and by its plurality and social mobility. All of these characterizations influence the way a person sees and interprets the world. Especially a phase of life such as "adolescence" is influential, where young people experience more autonomy and differentiation in relation to the family and in which the time spent among peers gains a special dimension. School offers a fertile field where the adolescent, with their knowledge that has been constructed by family and society, establishes relations with the scientific universe, with the specific object, in schools and in the domain of health.

However, experimental studies have demonstrated that in certain "crystallized" social representations, the transformations that occur because of the pressure that comes from changes in society take place on the peripheral levels of the representational structure, while the core remains unchanged ("The theory of the central core" is described by Jean-Claude Abric in 1976, which is found in [12]). The peripheral elements are the elements that exercise a fundamental role in adapting the representation when there is an evolution of the context in which it was produced [13-17]. Only in the peripheral elements resides the change of interpretation and the integration of new foundations that are conveyed, such as in this case, by educational programs, with special participation by the media. Therefore, we cannot predict the extent to which the abandonment of the negative view on cancer with the advancement of age will guide the future actions of the research subjects to see the disease as a process that can be prevented, treated, and cured. We cannot make this prediction because the behaviour of the subject is not determined by the characteristics of the disease itself but by the representation that cancer assumes in the subject's most intimate rationality. Moreover, it is unknown how long it will take for the abandonment of negative views of cancer to occur. The current work constitutes one possible reading of the issues involving the current reality in a given population that is in a growth and adaptation phase. There is a gap between what people say and what they actually do, between speech and behaviour, and between the opus operatum of theory and the modus operandi of practice. This gap is hierarchized by the statistical method employed (quantitative) due to the types of answers that are not "spontaneous" but "provoked" by a questionnaire, which often requires selecting a position even in the absence of an opinion. These factors should be considered when one infers certain interrelated human attitudes and behaviors.

In this research, we investigate public and private school students, who are recipients of a formal education that is essentially based on a conception of scientific rationality where the only legitimate form of knowledge derives from the discoveries that are provided by "science". The prioritization of the biological dimension of cancer in Brazilian schools currently has the "study of the cycle of the diseases" as its central matter, particularly in the last four grades of elementary school. The emphasis is on disease and on the promotion of individual behaviours to avoid it, with little opportunity for students to build the belief that the living conditions that favour disease processes can also be modified. Although this "biologism" in education can help adolescents to be more assertive in their responses with the advancement of age/series, it is not the only source of knowledge (Table 2). Socializing agents, especially in current society, must also be included. These socializing agents exercise influence in an impersonal way, which is the case of television, the radio, the press, information networks, and all the media that reflect values and belief systems in the information that they disseminate.

However, in recent decades, in addition to the topics that are traditionally worked on, namely, health and education, the biopsychosocial issues have acquired greater visibility. Furthermore, Brazilian schools were compelled to address emerging problems such as AIDS, the abuse of alcohol and other drugs, social violence, and even cancer. Because the incidence of cancer is very high, undoubtedly, it has become common that a) in a family, there is at least one story about a loved one or a friend who "has suffered or suffers from the disease" (Table 3); b) students have received information from the person who lived the experience; c) promotional or prevention campaigns have been developed that grow through mass communication; and d) songs, poems, films, and all types of stories have been written in which cancer appears as "someone" who can destroy and devour, which popularizes this type of expression before a person obtains an objective understanding of what the disease essentially is. Although schools promote "scientific knowledge", teachers and students as actors in a changing society carry with them knowledge that is built on a daily basis, in the social, family, and professional contexts [18]. This is the knowledge that they bring to school. Knowledge that does not reproduce wisdom is stored in science and is destined to remain there, but knowledge that reworks, according to its own convenience and according to its means, is "another type" of knowledge. This knowledge is adapted to particular needs and criteria in a precise social context. Identifying elements of this knowledge and establishing relationships with scientific knowledge is an important step to comprehend the barriers and detours that can be registered both inside and outside the school space.

In Brazil, many local initiatives have been undertaken to implement health education. The challenge is to build references to guarantee this right for everyone. Although the teaching methodology and its scope that are developed in this study's participating schools are not the subject of the current research, they have most likely contributed to the results that are presented here. This understanding is reinforced 
by the fact that the participation of teachers and the curricular work that they coordinate occupies the fourth place in the students' process of obtaining information on cancer, according to the research data (Table 2). All of this process, coupled with the influences of family and the social environment surrounding the student form the so-called "cultural baggage". Students receive from society the concepts and matrices with which they think and build their own representations, based on a practical orientation and focused on building a common reality. This changeable representation contributes or will contribute, as much as possible, to the processes of the formation of conduits and the guidance of individuals in their community and around it.

In this descriptive analysis, the fact that the negative view is prevalent among males draws attention (Figure 2). This statistically significant difference can be partly attributed to the greater prevalence of girls at home compared to boys. The female students interact more with their parents or relatives, who exert broad influence and socialize and supervise children in different ways [19]. This coexistence, which is enriched with information and direct or indirect experiences in relation to cancer and other related issues, can reduce the chaotic vision of the disease. However, other factors probably exert some influence as well.

In the current context, it is appropriate to question whether the students can identify the disease. The questionnaire allowed a determination of the degree of student knowledge and satisfied this curiosity. First, $99.8 \%$ of the participants, regardless of age, gender, or place of study, had heard about cancer. The students who were interviewed tended to relate the object to the source of information, which is represented by the family, followed by television (Table 2). A dimension of the research certifies a dissemination of information that is generated inside the family. The origin of information was not influenced by education or socioeconomic level. Family was the main benchmark, followed by television, the internet, and teachers. The fact that family is the main source of information requires, on the one hand, that parents and children often "engage in conversation" and, on the other hand, that cancer is introduced as a point of discussion in interpersonal and parent-child relationships. "Daily conversations" must be emphasized because they are useful for receiving and providing an information flow that is crucial in the structuring of the entire social representation. In the course of these communicative interactions, the so-called "communication background" occurs. This background serves as a permanent scenario for the representations and is an inexhaustible source of content for them.

Through language, which is an excellent communication vehicle, in its various levels and forms, the entire arsenal of culture is transmitted, which is decisive in the shaping of social representations. In addition to the historical, economic, and ideological conditions in which social representations arise, the institutions or organizations with which the subjects and groups interact are essential. The social inclusion of individuals into certain groups, which is in this case, family, is also important. Although talking is not, as claimed popularly, a women's specialty, it is true that the knowledge regarding certain types of cancers that are referenced is higher in the female students than the male students. According to the American philosopher Sommers [20], this finding may be because "girls are more academically engaged" and can thus retain more information. However, probably family and social conviviality, with direct or indirect involvement with the disease, also contribute.

Of course, the private and domestic space that is granted to women in Brazil leads them to assume a type of living that is more committed to the adult universe and its problems, which is a direct consequence of disparate family socialization. In some ways, the differentiation according to gender reflects the type of education that girls receive. Girls are taught to behave like girls, and boys are taught to behave like boys. Children learn and internalize the social role that is assigned to each gender, which may explain the differences in terms of content and experience acquisition and in their transference. This particular submission of the female adolescent to the "family" makes them value the roles of caretaker more, such as being attentive, knowing their interior side, developing emotional bonds, etc. These roles and specific types of knowledge become natural based on what society considers acceptable.

Information that is linked to the curriculum and educational phase of the students is not excluded from this interpretation. The reading of specific material, including newspapers, magazines, textbooks, and the internet, is referenced. These sources also contribute to the concreteness of knowledge and have significant backing in the figure of the "teacher".

For illustrative purposes, the survey recorded a higher proportion of readers in private school. Although there are socio-economic differences between the two groups, they were not decisive in the choice of resource that was used. The difficulty of accessing cultural assets (libraries, broadband internet, and magazines), which was seen on the public network [21], is partly responsible for the reduced importance of reading compared to other sources of information (i.e., TV news and doctors), which enable the establishment, in the long run, of a type of "compensation" or "content balance".

In relation to the role of the media itself and according to data that were contributed by the 2015 Brazilian Media Research, television is the most used channel of information by Brazilians. This study revealed that $95 \%$ of the 18,000 people who were interviewed watch TV, and $73 \%$ do so daily. On average, Brazilians spend $4 \mathrm{~h} 31 \mathrm{~min}$ per day exposed to television from Monday to Friday, and $4 \mathrm{~h} 14 \mathrm{~min}$ per day on weekends. Another interesting finding is that young people from 16 to 25 years old watch approximately $1 \mathrm{~h}$ less of television every day of the week ( $4 \mathrm{~h} 19 \mathrm{~min}$ ) than adults who are over 65 years of age ( $5 \mathrm{~h} 16 \mathrm{~min}$ ). When the channel of information is the internet, these timetables change significantly, and during the week, on average, the values are $5 \mathrm{~h} 51 \mathrm{~min}$ and $2 \mathrm{~h} 53 \mathrm{~min}$ of exposure to the internet for young people and older people, respectively [22]. In a way, both sources of mass communication, as well as radio and newspapers, play an important role in the formation of the social representation of cancer. Although radio is traditionally regarded as the second most used channel of communication, according to the survey, only $30 \%$ of Brazilians indicate that they listen to the radio. Considering these data, the information that is currently contributed by the radio, which is essentially dedicated to economics and publicity, is assumed to be less among young people in terms of information and the dissemination of culture. This assumption is made primarily because of the advent of the internet, which has arguably become the primary host of radio services.

We do not analyze here how much veracity there is concerning the information that is collected in this respect or the degree of information that is captured and retained by the receivers in term of reproducibility because the purpose and logic of the messages that are transmitted respond to a particular socio-historical context. According to some theorists, mass media imposes the topics that are addressed in everyday conversations, which are situations where the representations are generated and developed freely $[10,23]$. In this way, the public perception of the so-called "relevant issues" is built based on the information that is transmitted by the media. In this 
sense, cancer is presented mostly as a risk instead of as something fatal, constituting therefore a "rationalized danger". Media discourses that are interested in the issue are numerous but are simultaneously prescriptive and promote the undergoing of "this or that exam". The linguistic-discursive approach employed makes an apology for the "hygiene of life", basically based on three aspects, being the feeding, the physical activity and the systematic tracing, the premonitory proofs of the disease. From the news that is published in Brazilian media that mentions the term cancer, $55 \%$ was produced abroad and only $38 \%$ had its origin in Brazil [24]. This result expresses the appreciation and preponderance of the international scientific community regarding cancer rather than the little that has "apparently" been done in the country. One can infer that the cancers that are more visible in news stories include breast, skin, uterus, prostate, and lung cancer, while other cancers that are also relevant are omitted or poorly broadcast (such as gastric, colorectal, oropharyngeal, and endometrial cancer).

The disease is important only while the patient suffers from it, and after this, it lacks relevance, which gives the false impression that there is no story to tell after cancer. In fact, topics such as "treatment, epidemiology and new diagnostic technologies" represent a significant percentage in the reports, while cure is a less pervasive topic [24]. In the rare cases when a cured patient is contacted, they are seen as a "hero", an example of perseverance. Additionally, the stories assume a moralizing tone, and the villain is always "the tumor".

This contribution of the media permeates the representations of the disease and is reflected in the conduct of individuals, groups and communities [25]. Therefore, it is understandable that the students in this research cite, in addition to the family, television and the internet as the main sources of information because they are genuine reservoirs of "parallel education".

The "supposedly correct" interpretation of the facts or events that is reported by the media is not exclusively dependent on the individual, while the receiver and absorber of information requires a connection to other knowledge that forms part of his daily life, his story. Individuals do not simply reproduce the information they receive, they represent it, i.e., they redefine it. They appropriate the information, give a new meaning to the language, and anchor it in the common base of their knowledge. This process of construction is produced in tête à tête interactions and within the framework of a social context, which is marked not only by a collective cultural archive but also by the particular position that the individual assumes within the social structure, as well as by the membership in specific groups in which the individual acts.

Considering formal communication in the field of health requires an ethical commitment and an engagement with the "other" person so that the other gains autonomy and confidence in their attitudes and choices, which is a fact that still seems far from being achieved in Brazil.

Science, culture, media, legislation, and common sense interact in a process of multiple implications, value judgments, social relations, and communication to create social representations where knowledge is integrated and objects are given a new meaning. Based on these concepts, the disease is seen by adolescents from three perspectives: a) as "destruction", where the terms are centered on death, especially when someone from the family or some friend suffers from the disease; b) under the aegis of "incurability", whose association with death is equally divided among opinions concerning the binomials of life/death and heal/get sick; and c) "resolution" or cure, which depends on early diagnosis and treatment. Accordingly, $45 \%$ of the respondents from public schools and $40 \%$ of the respondents from private schools believe in the possibilities of a cure. These percentages are reduced to $40 \%$ and
$35 \%$, respectively, when someone they know suffers from the disease. In terms of "severity", females, according to the incorrect respondents, suffer the most (Table 1).

Of course, the impact of an illness such as cancer profoundly influences the ecological, social, and cultural contexts of family dynamics. Before the illness, the social identity of the family is affected in its psychological, instrumental (activities of everyday life), and social functioning. Members near the patient with whom there are ties of mutual help and care are an integral part in the trajectory of the illness. Cancer affects each family member emotionally and cognitively. It also has an impact on their daily conduct, future projects, the meaning that is given to oneself or others, and even what they consider to be the meaning of life. It is logical to think that young people share these experiences with variable results depending on their age, degree of proximity to the patient, the importance of the patient to the family group, and the "severity" and "outcome" of the disease.

\section{Conclusion}

The quantitative methodology that is developed in this research allowed the identification of how the figurative models of psychic activity around cancer are established and how they change over time. These models consist of various elements of sense and meaning that circulate in society, with special participation by the media, and come from different experiences of the subject giving the social knowledge not only a subjective but also a symbolic dimension. In the long wait for a cure, it is insufficient to consider the biological side of the disease through biotechnology, which commonly occurs, if the social side is ignored. In fact, the goal of detection and early diagnosis is pursued, and the failure of permanent and invisible exclusion is hidden, where economic, social, and cultural factors anchor the individual in the depths of their indomitable human nature. The euphoric success of "biomedicine" hides the hopeless failure of social "being". Cancer cannot be understood and successfully solved when it is analyzed from a purely biological perspective. As a social phenomenon, it displays the same problematic aspects that are seen in the major collective issues of the present time and is defined by complex and sometimes contradictory situations, which are presented here.

\section{Acknowledgements}

We especially thank Prof. Dr. Fernando Gil Villa, whose work "La cara social del cáncer" was a source of inspiration for our work.

\section{References}

1. Goss PE, Lee BL, Badovinac-Crnjevic T, Strasser-Weippl K, Chavarri-Guerra $\mathrm{Y}$, et al. (2013) Planning cancer control in Latin America and the Caribbean. Lancet Oncol 14: 391-436.

2. Stewart BW, Wild CP (2014) World cancer report 2014. IARC Press, Lyon France, p: 620

3. Instituto Nacional de Câncer (2015) Estimativa 2016-incidência de cânce no Brasil. Ministério da Saúde. Instituto Nacional de Câncer José Alencar Gomes da Silva (INCA), Rio de Janeiro, p: 122.

4. Pesquisa CNI-IBOPE (2012) Retratos da sociedade brasileira: Saúde Pública CNI, Brasília, p: 67

5. Skott C (2002) Expressive metaphors in cancer narratives. Cancer Nurs 25 230-235.

6. Domínguez MF (2009) El cáncer desde la mirada del niño. Alianza Editorial Madrid, p: 208

7. Armstrong BK, White E, Saracci R (1992) Principles of exposure measurement in epidemiology. Oxford University Press, pp: 137-235.

8. Anchieta VCC, Galinkin AL (2005) Policiais civis: Representando a violência Psicol Soc 17: 17-28. 
Citation: Cardoso EB, Schilling FI (2017) Social Representations of Cancer in the Perception of Students Who Attend Brazilian Public Schools. J Health Educ Res Dev 5: 224. doi: 10.4172/2380-5439.1000224

9. International Agency for Research on Cancer (2015) Consumption of red meat and processed meat. In: Monographs Evaluations Carcinogenic Risks Humans. IARC Working Group (Editor). IARC, Lyon, pp: 6-13.

10. Moscovici S (1979) El Psicoanálisis, su imagen y su público. Huemul, Buenos Aires, p: 291.

11. Knapp E, Suárez M, Mesa M (2003) Aspectos teóricos y epistemológicos de la categoría representación social. Rev Cubana Psicol 20: 23-34.

12. Abric JC (2001) Les représentations sociales: développements récents. Psychol Soc 4: 84

13. Abric JC (1994) Les représentations sociales: Aspects théoriques. In: Pratiques Sociales et Représentations. Abric JC (ed.), Presses Universitaires de France, Paris 187-203.

14. Abric JC (1996) Specific processes of social representations. Soc Represent 5: $77-80$.

15. Flament C (1994) Structure, dynamique et transformation des representations sociales. In: Pratiques Sociales et Representations. Abric JC (ed.), Presses Universitaires de France, Paris, pp: 37-57.

16. Bonardi C, Roussiau N (1999) Les représentations sociales. Dunod, Paris, p: 250.

17. Flament C, Rouquette ML (2003) Anatomie des idées ordinaires: Comment étudier les représentations socials. Armand Colin, Paris, p: 175.
18. Maia LSL (2001) O que há de concreto no ensino da matemática. Rev Zetetiké 9: 77-98.

19. Hagan J, Simpson J, Gillis AR (1987) Class in the household: A power-control theory of gender and delinquency. Am J Soc 92: 788-816.

20. Sommers $\mathrm{CH}(2000)$ Where the boys are. The myth of the fragile girl. In: The War Against Boys how Misguide Feminism is Harming Our Young Men. Sommers CH (ed.), Simon \& Schuster Paperbacks, New York, p: 256.

21. Neto JS, Jesus G, Karino C, Andrade D (2013) Uma escala para medira infraestrutura escolar. Estudos em Avaliação Educacional 24: 78-99.

22. Brasil (2014) Presidência da República. Secretaria de Comunicação Social In: Pesquisa Brasileira de Mídia 2015: Hábitos de Consumo de Mídia Pela População Brasileira. Secom, Brasília, p: 153.

23. Adorno TW (2002) Indústria cultural e sociedade. Paz e Terra, São Paulo, p: 16.

24. Jurberg C, Gouveia ME, Belisário C (2006) Na mira do câncer: O papel da mídia brasileira. Rev Bras Cancerol 52: 139-146.

25. Banchs MA (2007) Las Representaciones sociales: una teoría sobre las relaciones entre ciencia y sentido común. In: Representaciones Sociales Teoría e Investigación. Rodríguez TS, García MLC (eds.), Universidad de Guadalajara, Centro Universitario de Ciencias Sociales y Humanidades. Guadalajara, Jalisco, México, pp: 219-253. 